suche, welche wir in diesem Augenblicke unternommen haben, lassen uns aber hoffen, dass wir in Kurzem vollkommen schöne Producte werden vorlegen können.

Um uns von der Identität unseres Aventurins mit dem der venetianischen Fabriken zu überzeugen, haben wir beide durch ein ausgezeichnetes $\mathrm{Ob}$ erhäu ser'sches Mikroskop beobachtet, und wir erkannten, dass in dem einen wie in dem andern Glase das Kupfer in regelmässigen Octaëdern krystallisirt war.

Wir wollten in dieser Abhandlung nicht die verschiedenen theoretischen Fragen behandeln, welche bei der Fabrication des Aventurins entstehen, und nicht untersuchen, ob die Reduction des Kupfers der directen Einwirkung des Eisenoxyduloxyds im Hammerschlag, oder vielleicht dem metallischen Eisen, welches er häufig enthält, auf das Kupferoxydul zugeschrieben werden muss: oder ob vielleicht ein Eisenoxydulsilicat entsteht, welches durch seine Einwirkung auf das Kupferoxydulsilicat metallisches Kupfer erzeugen würde.

\title{
LXIX.
}

\section{Neue Verbindung von Brom und Bor, Bromborsäure und Ammoniakbromborat.}

\section{Von \\ Poggriale.}

(Compt. rend. T. XXII. p. 124.)

Ich habe die Bromborsäure bereitet, indem ich Bromdämpfe über ein Gemenge von verglaster Borsänre und rothglühender Kohle leitete. Der Apparat, dessen ich mich bediente, ist demjenigen sehr ähnlich, welchen 0 ersted $t$ und $D$ u mas zur Bereitung der Chlorkieselsüure und Chlorborsäure angewendet haben. Derselhe besteht aus einem Porcellanrohr, an dessen einer Seite man eine kleine Retorte, welche das Brom enthält; anpasst, an dessen andere Seile eine Vorlage mit einem zum Auffangen des Gases zweckmässig gebogenen Rohr angefügt ist. Wenn die Mischung von Kohle und Borsäure in die Röhre eingetragen ist, erhitzt man wenigstens eine halbe Stunde, um den Wasserdampf auszutreiben, welcher im Gemisch enthalten ist; man verflüchtigt nun nach 
und nach das Brom und sammelt das Gas über Quecksilber, welches den Ueberschuss des Broms absorbirt.

Bei der Bereitung dieses Gases habe ich alle Vorsichtsmaassregeln angewandt, welche $\mathrm{D} \mathrm{u} \mathrm{m}$ a s für die Chlorborsäure angegeben hat, um dieoBildung einer zu grossen Menge Bromwasserstoffsäure zu vermeiden. Eben so ist es nöthig, die gekrümmte Röhre zu wechseln, weil dieselbe leicht durch das Quecksilberbromür und die Borsäure verstopft wird, welche letztere nach kurzer Zeit die Wände der Vorlage bedeckt und wohl auch in das Rohr tritt.

Wenn man den Versuch sehr sorgfältig macht, so enthalten die Gase wesentlich 3 Volumen Kohlenoxyd und 2 Volumen Bromborsäure; aher man findet darin sehr häufig Bromwasserstoffsäure, welche durch dạs Wasser der Stöpsel erzeugt ist.

Ich habe es versucht, die Bromborsäure dadurch zu erhalten, dass ich über Bor, welches in einem Glasrohr mitHülfe einer Lampe erhitzt wurde, Brom hinwegleitete. Ich konnte dabei stets nur schwache Spuren des Gases erhalten. Diess beruht vielleicht darauf, dass ich mit stark erhitztem Bor arbeitete. Ich glaubte, dass reine Bromborsäure sich erzeugen würde, wenn ich Brom über Boreisen hinwegleitete. Das Boreisen wurde erhalten durch Fällen von neutralem schwefelsaurem 0xyduloxyd durch borsaures Natron und Behandeln des borsauren Eisenoxyduloxyds in heller Rothglühhitze mit Wasserstoff; die erhaltene Substanz aber, welche von silberweisser Farbe war, gab nur Eisenbromür. Dieser Versach hat mich veranlasst, das Product der Einwirkung des Wasserstoffgases auf das borsaure Eisenoxyd genau zu untersuchen. $\mathrm{Zu}$ diesem Ende liess ich es in Wasser sieden; nach Abdampfen der Solution erhielt ich Borsäure, reines Eisen blieb zuriick. Mit Schwefelsüure, welche mit ihrem halben Gewicht Wasser verdiunnt war, behandelt, entwickelte sich Wasserstoff, und in der Flüssigkeit zeigte sich eine weisse Substanz, welche Borsäure war. Diese Versuche scheinen darzuthun, dass das Eisenborat sich durch Einwirkung von Wasserstof in Eisen und Borsäure zerlege.

Die Bromborsäure ist gasförmig und farblos, sie hat einen sehr stechenden Geruch und einen sehr sauren Geschmack, ähnlich denen der Chlorwasserstoffsäure. Sie röthet das Lakmuspapier stark. Brennende Körper verlöschen darin; bei Berührung mit der Luft giebt sie weisse Dämpfe. Wärme zerlegt sie nicht.

Das Gas hat zum Wasser dieselbe Verwandtschaft wie die Chlor- 
borsäure. Wenn man die Lösung abdamplt, so erhält man einen Rückstand von Borsäure und es entwickelt sich Bromwasserstoffsäure. Die Bromborsäure zersetzt demnach, wie die Chlorborsäure und Fluorborsäure, das Wasser.

Wenn man ein mit Bromborsiuregas gefiilltes,Proberöhrchen einige Augenblicke mit Wasser schüttelt, so brennt die Portion, welche nicht verschluckt worden ist, mit blauer Flamme; entzündet man aber unmiltelbar, ohne abzuwarten, dass die weissen Dämpfe sich absetzen oder im Wasser lösen, so brennt das Gas mit einer grünen, in Blau nüancirenden Flamme. Die grüne Farbe rührt sicher von der Gegenwart der Borsäure in den weissen Dämpfen her. Diess Verhalten kann mit Vortheil zur Unterscheidung der Bromborsäure und Fluorborsäure von andern Gasen, welche an der Luft weisse Dämpfe bilden, angewendet werden.

Wenn man einige Blasen trocknes Chlor in ein Proberöhrchen, welches Bromborsäure enthält, bringt, so entstehen sofort rothbraune Dämpfe von Brom.

Die Dichtigkeit dieses Gases, durch Rechnung bestimmt, ist $=8,4643$.

Die Bromborsäure, welche mit Wasser Borsäure und Bromwasserstoffsäure giebt, muss aus einem Volumen Bor und drei Volumen Bromdampf gebildet sein.
3 Volumina Brom
16,1799
1 Volumen Bor
2 Volumina Bromborsäure 16,9286
1 Volumen Borsäure
8,4643 .

Hiernach ist die Formel:

$$
\mathrm{B} \mathrm{Br}_{3} \text {. }
$$

Man kann die Zusammensetzung der Bromborsäure auch bestimmen, indem man die Verhältnisse des durch die Kohle gebildeten Kohlenoxyds und der Bromborsäure, die Borsäure und das Brom vergleicht, wie diess bei der Chlorborsäure Dumas gethan hat.

Ammoniakbromborat. Wenn man ein Volumen Bromborsäure mit anderthalb Volumen Ammoniakgas mengt, so erhält man ein weisses pulverförmiges, füchtiges, stechend schmeckendes Salz. Es ist in Wasser löslich und wird davon in Bromhydrat und Ammoniakborat zersetzt. 